
Military Technical College
Kobry Elkobbah,
Cairo, Egypt

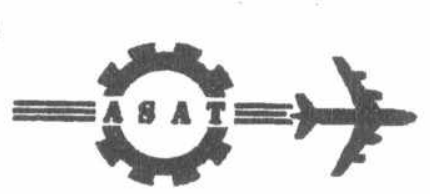
$8^{\text {th }}$ International Conference
On Aerospace Sciences \&
Aviation Technology

\title{
EFFECT OF SPECIMEN THICKNESS ON FATIGUE CRACK GROWTH BEHAVIOUR UNDER CONSTANT AND VARIABLE AMPLITUDE LOADING
}

\author{
M.M.I. HAMMOUDA*, S.S.E. AHMAD** and M.H. SELEEM**
}

\section{ABSTRACT}

Mode I fatigue crack growth behaviour was experimentally investigated under constant and following the application of a single spike overload. Different specimen thicknesses were investigated at different overload ratios. A previously developed crack tip deformation model to correlate fatigue crack growth behaviour following $\mathrm{i}$ a single overload cycle was used to correlate that behaviour for different specimen thicknesses. It was found that the effect of specimen thickness on the fatigue crack growth behaviour under constant amplitude of loading is marginal especially at growth rates greater than $10^{-4} \mathrm{~mm} / \mathrm{cycle}$. The retardation due to the application of a tensile single overload decreases with the increase in specimen thickness. Good agreement between relevant experimental results and those predicted using three dimensional crack tip deformation parameter was found.

\footnotetext{
* Professor, Dpt. Of Mechanical Eng., Al- Azhar University, Cairo, Egypt

** Assistant Prof., Dpt. Of Materials Eng., Zagazig University, Zagazig, Egypt.
} 


\section{KEYWORDS}

Fatigue Crack Growth, Constant Amplitude Loading, Single Overload, Plate Thickness, Crack Tip Deformation

\section{INTRODUCTION}

The process of fatigue crack propagation is complicated by the influence of many mutually interdependent factors, such as methods of loading, environmental conditions and the composition of materials. Cracks contained within structures show a high degree of triaxiality in the vicinity of their fronts. The load carrying capacity of those structures has been assessed, in most cases, with fracture mechanics concepts assuming simplifications relevant to their stress-deformation state.

To understand the scale shifting effects from laboratory specimens to the structure components, it is imperative to know the effect of the specimen thicknesses on the fatigue crack growth, FCG, behaviour under different loading patterns. A survey of some limited experimental data available in the literature concerning the effect of increasing the thickness on FCG due to constant amplitude loading, CAL, indicates a disagreement and the three contradictory conclusions of (a) no effect at all [1], (b) an accelerated growth with a high degree of plane strain [2,3] and (c) a reduced growth rate [4] have been documented. The results available so far suggest that such effects could be dependent on the material, the loading conditions and the investigated range of growth rates.

For the fatigue design of structures, the crack propagation stage is of greatest significance since it accounts for the majority of the fatigue life. However, such a design is frequently carried out by making use of constant amplitude fatigue data. Most structural members and machine components are subjected to varying amplitude loading, VAL, having either a regular or random pattern. Depending on the change in the applied stress level, the fatigue life of the structures under this latter stress may be increased or decreased.

Although the effect of specimen thickness on the FCG behaviour following a single overload was experimentally investigated [5], no attempts had been made to 
correlate this behaviour and take into consideration the effect of thickness. An understanding and correlating of this behaviour is required in order that an adequate account can be taken of the variable amplitude response of many components and structures in engineering critical assessments and residual life estimations.

The objectives of the present work are to experimentally investigate the effect of specimen thickness on the FCG behaviour under constant amplitude loading and following the application of a single overload. Moreover, the effect of overload ratio, OLR = overload stress/ base load stress, is also investigated. Finally, the capability of the crack tip deformation parameter, CTDP, to describe the effect of specimen thicknesses on FCG behaviour under CAL and that following the application of a single peak tensile overload, SOL, was examined.

\section{EXPERIMENTAL WORK}

An experimental program with the parameters listed in Table 1 was designed to demonstrate the effect of the specimen thickness on the FCG behaviour under CAL and that following the application of SOL. The material used in this study was a commercial aluminum. The material was supplied in the form of plates with different thicknesses and was tested in the "as-received" conditions. The material had E = 68 $\mathrm{GPa}$, an ultimate tensile strength of $160 \mathrm{MPa}$ and $0.2 \%$ proof stress $=100 \mathrm{MPa}$. The chemical composition in mass percentage was $0.13 \% \mathrm{~S}, 0.09 \% \mathrm{P}, 0.025 \%$ $\mathrm{Mn}, 0.03 \% \mathrm{Ni}, 0.05 \% \mathrm{Cr}, 0.25 \% \mathrm{Cu}, 0.16 \% \mathrm{Ti}, 0.035 \% \mathrm{Sn}$ and balance Al.

The plates had the final dimensions of $150 \mathrm{~mm} \times 40 \mathrm{~mm} \times 2 \mathrm{t} \mathrm{mm}$ with a starter edge notch machined to a depth of $a_{0}$ and a tip radius of $0.4 \mathrm{~mm}$ at the mid-section along the width with the avoidance of residual stresses. The specimens were cut so as to have their longitudinal direction coincident with the rolling direction. The surface of one side of the specimens was polished along the expected path of cracking. The tests were performed in laboratory ambient conditions with controlled sinusoidal constant amplitude pulsating loads at a frequency of $25 \mathrm{~Hz}$ under the load control condition on a servo-hydraulic MTS universal machine. All tests were carried out at zero stress ratio. The transient cycle was applied monotonically. The crack length prior to the application of this transient cycle, a TRC, is indicated in Table 1. 
Table 1. The experimental program in the present work

\begin{tabular}{|c|c|c|c|c|}
\hline $\begin{array}{c}\text { Specimen } \\
\text { thickness, 2t }\end{array}$ & $\begin{array}{c}\text { Initial crack } \\
\text { Length, } \mathrm{a}_{0}\end{array}$ & $\mathrm{a}_{\text {TRC }}$ & $\begin{array}{c}\text { Base load } \\
\text { stress, MPa }\end{array}$ & OLR \\
\hline $3 \mathrm{~mm}$ & $6.50 \mathrm{~mm}$ & & 39 & \\
\hline 6 & 3.65 & & 39 & \\
\hline 10 & 4.25 & & 43 & \\
\hline 16 & 7.50 & & 33 & \\
\hline 19 & 7.00 & & 30 & \\
\hline 6 & 3.25 & $4.1 \mathrm{~mm}$ & 38 & 1.50 \\
\hline 6 & 3.75 & 4.9 & 39 & 1.75 \\
\hline 3 & 2.50 & 3.5 & 30 & 2 \\
\hline 6 & 3.65 & 5.1 & 41 & 2 \\
\hline 10 & 4.25 & 4.7 & 51 & 2 \\
\hline
\end{tabular}

The crack length was monitored by a traveling microscope with a magnification of 100. Data of crack length against the corresponding number of cycles were obtained. Analyses were performed for fatigue cracks having their tips lying outside the monotonic plastic zone generated originally at the root of the starter notch which was estimated for the base load preceding the application of the transient cycle. FCG rates were calculated from each pair of successive data using the finite difference method. The mode I stress intensity factor, SIF, range, $\Delta \mathrm{K}_{\mathrm{I}}$, was calculated for $\mathrm{a} / \mathrm{W}$ $<0.6$ from [6]

$$
\Delta \mathrm{K}_{\mathrm{I}}=\Delta \sigma \mathrm{w}^{0.5}\left[1.99(\mathrm{a} / \mathrm{w})^{0.5}-0.41(\mathrm{a} / \mathrm{w})^{1.5}+18.7(\mathrm{a} / \mathrm{w})^{2.5}-38.48(\mathrm{a} / \mathrm{w})^{3.5}+53.85(\mathrm{a} / \mathrm{w})^{4.5}\right]
$$

where $\Delta \sigma$ is the applied stress range, $a$ is the current crack length and $w$ is the width of the specimen.

\section{RESULTS AND DISCUSSION}

\section{Constant Amplitude Loading}

FCG rates, da/dN, and SIF range, $\Delta \mathrm{K}$, for the different specimen thicknesses are presented in Fig. 1. The figure reveals that the crack grows faster at a higher degree of plane strain. i.e. in the thicker specimens at low growth rates. A similar increase in 
growth rates with increasing thickness was reported by Kang and Liu [2]. However at higher growth rates, the situation appears to change distinctly, and the effect of thickness is only marginal.

Hammouda and Sallam [7] proposed a parameter based on the deformation accommodated ahead of the crack tip, CTDP, to correlate FCG data in the form:

$\mathrm{CTDP}=\left(\frac{\delta_{\mathrm{s}}}{\delta_{\mathrm{r}}}\right)^{0.54} \frac{\Delta \delta}{\mathrm{Y}^{2}}$

where $\delta_{s}$ and $\delta_{r}$ are respectively the maximum crack tip opening displacement of stationary and propagating cracks, $\Delta \delta$ is the cyclic crack tip opening displacement and $Y$ is the corresponding geometry correction factor. The details estimating of $\delta_{s}, \delta_{r}$ and $\Delta \delta$ is presented in [7]. This parameter was obtained based on two dimensional, 2-D, plane stress analysis. The present FCG data for different specimen thicknesses subjected to CAL were correlated by this parameter as shown in Fig. 2.

A modification of the CTDP was proposed by Hammouda et al [8] to be utilised for three dimensional, $3-D$, analyses by multiplying this parameter by a factor $F_{3}$. The factor $F_{3}$ represents the ratio of the crack tip deformation from $3-D$ analysis to its correspondence from 2-D analysis and given by $F_{1} F_{2}$,

$$
\begin{aligned}
& F_{1}=1-\alpha e^{-\eta M 1}-\gamma(z / t)^{2} e^{-\mu M} \\
& F_{2}=1-(b / t)^{0.22}\left[1-\mu(z / t)^{2}\right]\left[1-(z / b)^{2}\right] e^{\left[A-(z / b)^{2}\right]}+(z / t)^{2} e^{B}
\end{aligned}
$$

where

$$
\begin{aligned}
& M=\Delta_{m 2-D} / t, \\
& M 1=M^{\lambda}, \\
& A=-\gamma M^{0.35} /(a / b)^{0.5}, \\
& B=-\eta M^{\lambda} /\left[(a / b)^{0.3}(b / t)^{\alpha}\right],
\end{aligned}
$$

$\Delta_{\mathrm{m} 2-\mathrm{D}}$ is the monotonic plastic zone estimated from two dimensional analysis and $\mathrm{z} / \mathrm{t}$ represents the location along the crack front and $a$ and $b$ are respectively the height and the base of a triangular slit symmetrically made along the main throughthickness stationary crack having a straight front, TSSF. 
Table 2. Constants for equations 3 and 4

\begin{tabular}{|c|c|c|c|c|}
\cline { 2 - 5 } \multicolumn{1}{c|}{} & \multicolumn{2}{c|}{$F_{1}$} & \multicolumn{2}{c|}{$F_{2}$} \\
\cline { 2 - 5 } \multicolumn{1}{c|}{} & $\Delta_{\mathrm{ms}}$ & $\Delta \delta_{\mathrm{ss}}$ & $\Delta_{\mathrm{m}}$ & $\Delta \delta_{\mathrm{s}}$ \\
\hline$\alpha$ & 0.6 & 0.22 & 0.8 & 0.8 \\
\hline$\eta$ & 2.92 & 0.75 & 1.76 & 2.88 \\
\hline$\mu$ & 2.73 & 0.86 & 2.5 & 1 \\
\hline$\gamma$ & -0.25 & 0.11 & 0.84 & 0.64 \\
\hline$\lambda$ & 1.1 & 0.8 & 0.75 & 0.75 \\
\hline
\end{tabular}

The ratio of the $\Delta_{\mathrm{ms}}$ and $\Delta \delta_{\mathrm{ss}}$ along the front of the TSSF to the corresponding value from 2-D plane stress analysis, i.e. $\Delta_{\mathrm{m} 2-\mathrm{D}}$ and $\Delta \delta_{\mathrm{s} 2-\mathrm{D}}$, is $F 1$. The factor $F 2$ is the ratio of $\Delta_{\mathrm{m}}$ and $\Delta \delta_{\mathrm{s}}$ along the front of stationary cracks to the corresponding values of a TSSF at the same local crack depth $\Delta_{\mathrm{ms}}$ and $\Delta \delta_{\mathrm{ss}}$. The factor $F_{3}$ is geometry dependent since it accommodates the effect of the plate thickness and the shape of the crack front. Each of the functions $F_{1}$ and $F_{2}$ contains five fit parameters to reflect the effect of the applied load, the plate thickness and the geometry of the crack front on the local values of both factors.

A correlation of FCG data using the CTDP $\times$ F3 is shown in Fig. 3. The correlation was made for $F C G$ on the specimen surface, i.e. $z / t=1$, in the equations of $F 1$ and F2. The data in Figs. 2 and 3 indicate that there is no significant effect of specimen thickness on FCG behaviour in the case of CAL especially at higher growth rates. Further, the increase in the specimen thickness leads to an increase in the difference between the correlations made by the present 2-D and 3-D analyses.

The effect of specimen thickness on FCG has been investigated by many workers. It has often been associated with the state of stress and strain at the crack tip [9]. It is known that a transition from plane strain to plane stress occurs when the size of the crack-tip zone reaches a certain proportion of the specimen thickness and that this transition distinctly affects FCG rates. Unfortunately, it is not easy to generalize since, reports indicating no effects [10], positive [11] and negative [9] influence have been recorded. Thus, plane stress-strain transition does not conclusively explain the change in crack growth rates.

From the view point of closure, Schijve [12] stated that the increase in specimen thickness leads to a relatively smaller part of the crack front in plane stress and consequently less effective crack closure. Whether this should fully account for faster 
crack growth in thicker materials is doubtful because the thickness effect on cracking rate is also observed if the closure stress is less than the minimum stress.

\section{Single Tensile Overload}

FCG behaviour for two plates thickness, i.e. $2 \mathrm{t}=6 \mathrm{~mm}$, and $10 \mathrm{~mm}$ following the application of a single tensile overload is illustrated in Fig. 4. The overload ratio in the two cases is 2 . It is clear from this figure that the amount of crack growth retardation increases as the plate thickness decreases. Those results confirm with the experimental results on a BS 4360 Grade 50D carbon-manganese structural steel obtained by Shuter and Geary [14].

The CTDP in equation 2 was used to predict FCG behaviour following the application of SOL. The prediction was based on either 2-D or 3-D analysis. In the two cases, an expression in the following form was used to describe the behaviour of the cyclic crack tip opening displacement following the application of a SOL:

$$
\frac{\Delta \delta}{\Delta \delta_{\text {Base }}}=1+\left(A+\frac{B}{1-\left(d a / a_{m}\right)}\right) e^{-\alpha /\left(1-\left(d a / a_{m}\right)\right)}
$$

where A, B and $\alpha$ are constants for loading block determined from the limiting conditions of this equation, da is the incremental crack tip advance and $a_{m}$ is the length of the retardation period as detailed in [13].

In the 2-D case, the constants $A, B$, and $\alpha$ appearing in equation 5 were calculated in the plane stress condition [7]. In the case of 3-D prediction, these parameters were estimated taking into consideration the effect of crack front shape and plate thickness using $F_{1}$ and $F_{2}$ with the constants of $\Delta_{m}$ given in Table 2. The predictions through this concept are illustrated in Figs. 4 and 5 respectively for the present 2-D and 3-D situations.

The data in Fig. 4 show that the difference between the experimental and the prediction is relatively small for a plate thickness of $6 \mathrm{~mm}$. In the case of specimen of $10 \mathrm{~mm}$ thick the difference increases. The used 2-D model [13] is based on the plane stress condition and this is not the case of thick specimen. This explains the 
large difference between the experimental and prediction in this latter case. Comparison between the experimental results and the prediction using the three dimensional analysis is presented in Fig. 5. The figure illustrates that that difference is small compared with the prediction of the 2-D analysis particularly for the specimens of $10 \mathrm{~mm}$ thick.

The increase in retardation with decreasing plate thickness were also observed in a 2024-T3 aluminum alloy [15] and were attributed to enhanced residual stresses and crack surface interference. Enhanced residual stresses in the overload plasitic zone were thought to account for the reduction in retardation with specimen thickriess in a. low-alloy pressure vessel steel and a high -strength corrosion resistant steel [16].

The FCG rate response to a single overload on thick specimen varies in the thickness directions [5]. At the center of thick specimens the FCG rates adopt higher value than at its surface or along the hole thickness of thin specimen. The present correlation indicating that the calculated overload plastic zone at the surface to be intermediate between the plane stress and plane strain values. At the center of thick specimen the plastic zone was close to the calculated plane strain plastic zone.

The effect of a single peak tensile overload ratio, OLR, on the subsequent FCG behaviour is illustrated in Fig. 6 together with the corresponding correlation due to the 2-D CTDP. The illustrated results are for the specimens $6 \mathrm{~mm}$ thick at: OLR of $1.5,1.75$ and 2 . It is clear from this figure that the rate of FCG at the base load preceding the overload, i.e. a< $a_{T R C}$, is controlled by the SIF range through the wellknown Paris expression. At the base load following the overload, BLF, a retardation in FCG took place to reach a minimum rate, at a certain crack length. As the crack tip advanced further, a continuous increase in the rates resulted in up to a crack length at which the rate started to match the basic FCG characteristics for the corresponding BLF.

With increasing the OLR, a significant increase in the amount of delay is observed. A similar observation was reported by other researchers [17-20]. For specified BLP and BLF, an increase in the OLR leads to a corresponding increase in the extent of the monotonic and cyclic crack tip plastic zones. The former extent is responsible for a blunter crack tip and more residual compressive stresses left on the crack surface behind the crack tip enhancing crack tip closure and resulting in a 
corresponding decrease in the crack tip deformation taking place in the course of the cycles following the overload [21-22].

\section{CONCLUSIONS}

The FCG behaviour of the tested specimens under CAL and single overloading patterns revealed the following conclusions:

1- Under constant amplitude loading there is no significant effect of the specimen thickness on the FCG behaviour especially at high growth rates.

2- The increase in the specimen thickness decreases the amount of retardation following the application of a single overload.

3- For a specified base load, an increase in the overload ratio leads to an increase in the retardation in the FCG rate under the constant amplitude load.

4- Good agreement between experimental FCG data following the application of a single overload and that obtained from 3-D crack tip deformation parameter was found especially for thick specimens.

\section{REFERENCES}

[1] Sullivan, A.M. and Crooker, T.W. "The effect of specimen thickness upon the fatigue crack growth rate of A516-60 Pressure vessel," Transaction of the ASME, pp 248-252, (1977).

[2] Kang, T.S. and Liu, H.W. "Fatigue crack propagation and cyclic deformation at crack tip," Int. J. Fracture, 10, pp 201-210, (1974).

[3] Dover, W.D. and Boutle, N.F. "The influence of mean stress and thickness on the fatigue crack growth of the aluminum alloy BS2L71," J. strain Anal. vol. 13, No.3, pp 129-139, (1978).

[4] Jack, A.R. and Price, A.T. "Effects of thickness on fatigue crack initiation and growth in mild steel specimens," Acta Metall., Vol. 20, pp 857-866, (1972).

[5] Shuter, D.M. and Geary, W. "Some aspects of fatigue crack growth retardation behaviour following tensile overloads in a structural steel," Fatigue Fract. Engng Mater. Struct, (19), pp 185-199, (1996).

[6] Sih, G.C. "Handbook of stress intensity factors" Inst. of Fract. and Solid Mech., Lehigh University, Pennsylvaia, USA, (1973).

[7] Hammouda, M.M.I. and Sallam, H.E.M. "An elastic plastic finite element simulation of crack tip deformation in fatigue," Presented at ICF8, Kiev., 1993, Advance in Fracture Resistance in Materials, International Congress on Fracture, Vol. 2, pp 3-10, (1996).

[8] Hammouda, M.M.I. Seleem, M.H., Sallam, H.E.M. and Ahmad, S.S.E. "Front development of a long fatigue crack during its growth," Fatigue Fract. Engng Mater. Struct, (20), pp 849-862, (1997). 
[9] McEvily, A.J. and Johnston, T.L., "Role of cross-slip in brittle fracture and fatigue," Int. J. Fracture Mech., 3, pp 45, (1967).

[10] Frost, N. E. and Dugdale, P. S. "The propagation of fatigue cracks in sheet specimens, "J. Mech. Phys. Solids 6, pp 92, (1958).

[11] Liu, H.W. "Fatigue Crack Propagation and the stresses and strains in the vicinty of a crack, " Appl. Mat. Res., 3, pp 229, (1964).

[12] Shijve, J. , "Four lecture on fatigue crack growth," Engng. Fract. Mech., Vol.11, pp 167, (1979).

[13] Hammouda, M.M.I., Ahmad, S.S.E. and Sallam, H.E.M. "Correlation of fatigue crack growth by crack tip deformation behaviour. Fatigue Fract. Engng Mater. Struct, (18), pp 93-104, (1995).

[14] Shuter, D.M and Geary, W. "The influence of specimen thickness on fatigue crack growth retardation following an overload" Int. J. Fatigue, Vol.17, No. 2, pp 111-119, (1995).

[15] Gan, D. and Weertman, J. “ Crack closure and crack propagation rates in 7050 aluminum," Engng. Fract. Mech., Vol. 15, pp 87, (1981).

[16] Bernard, P.J., Lindley, T.C. and Richards, C.E. "Fatigue crack growth under spectrum loads," ASTM STP 595, pp 78, (1976).

[17] Shin, C.S. and Fleck, N.A. "Overload retardation in a structural steel," Fatigue Fract. Engng. Mater. Struct., Vol. 9, pp 379, (1987).

[18] Bertel, J.D., Clwrivet, A. and Bathias, C. "R ratio influence and overload effects on fatigue crack mechanisms," Fracture 81, ICF 5, Vol. 2, pp 943, (1981).

[19] Von, EUW, E.F., Hertezberg, R.W. and Roberts, R. "Delay effects in fatigue crack propagation," ASTM STP 513, pp 230, (1972).

[20] Mills, W.J., Hertezberg, R.W. and Roberts, R. "Load interaction effects on fatigue crack growth in A514 steel," ASTM STP 637, pp 192, (1977).

[21] Robin, C., Louah, M. and Pluvinage, G. "Influence of an overload on the fatigue crack growth in steels," Fatigue Fract. Engng. Mater. Struct., Vol. 6, pp 1, (1983).

[22] Chen, B.D., Griffiths, J.R. and Lam, Y.C. " The effect of simultaneous overload and spot heating in crack growth retardation in fatigue," Engng. Fract. Mech., Vol. 44, pp 567, (1993). 


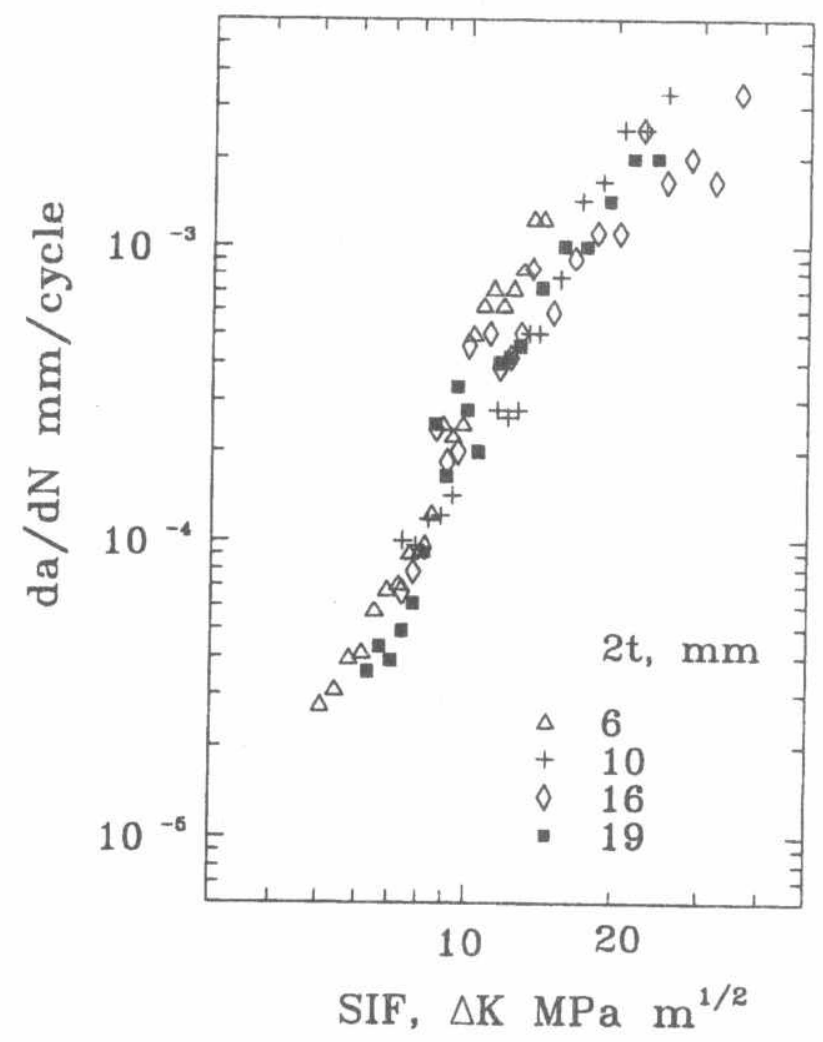

Fig.1 FCG rate in terms of SIF range for different specimen thicknesses, CAL

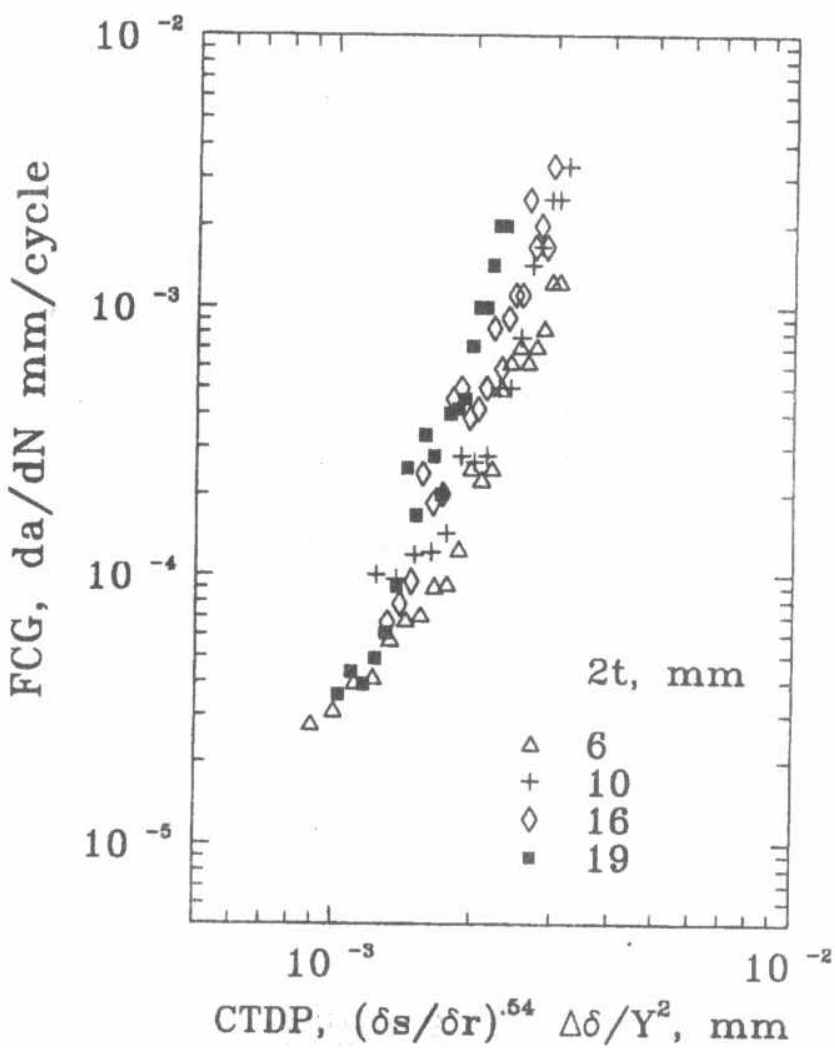

Fig. 2 FCG rate in terms of 2-D CTDP for different specimen thicknesses, CAL 


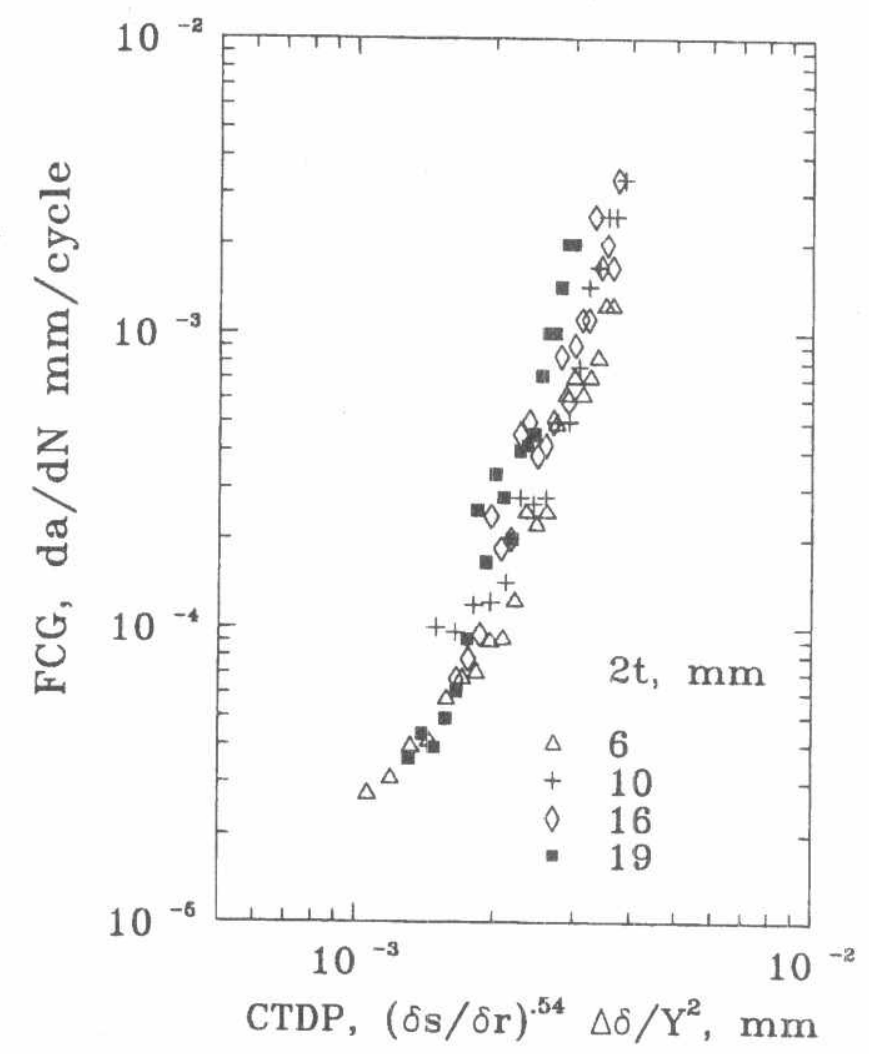

Fig. 3 FCG rate in terms of 3-D CTDP for different specimen thicknesses, CAL

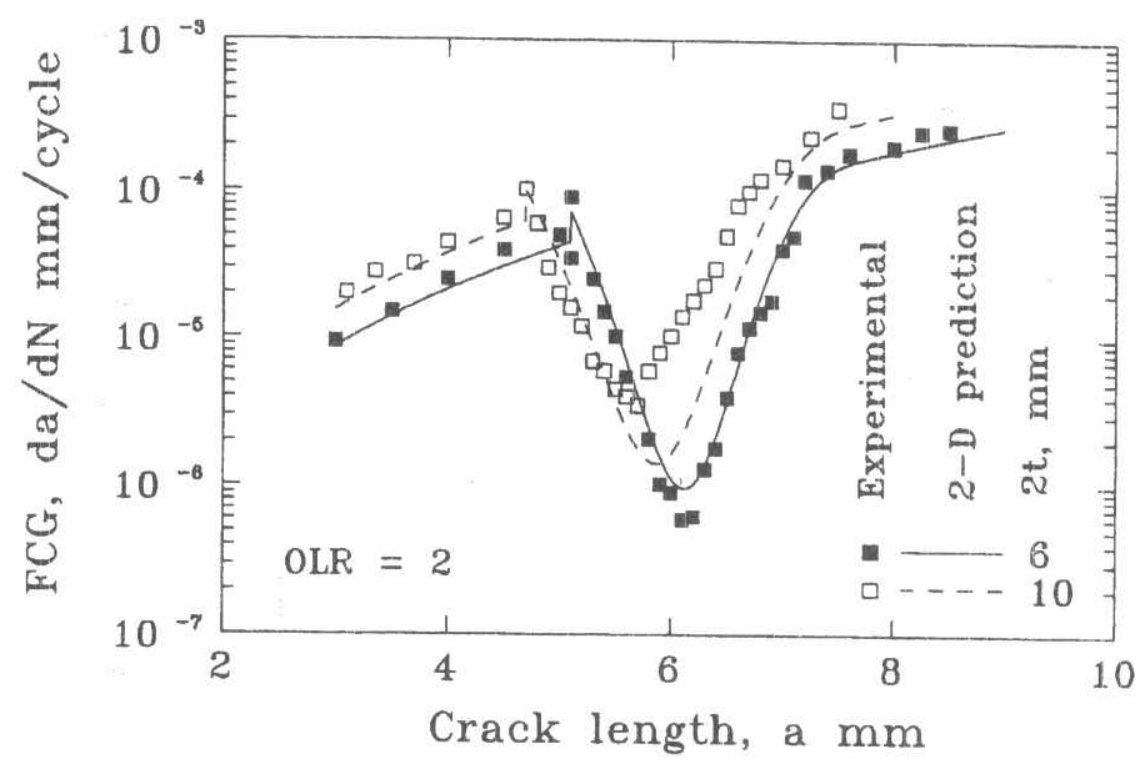

Fig.4 Comparison of experimental FCG data with the the prediction from $2-D$ analysis for different specimen thicknesses 


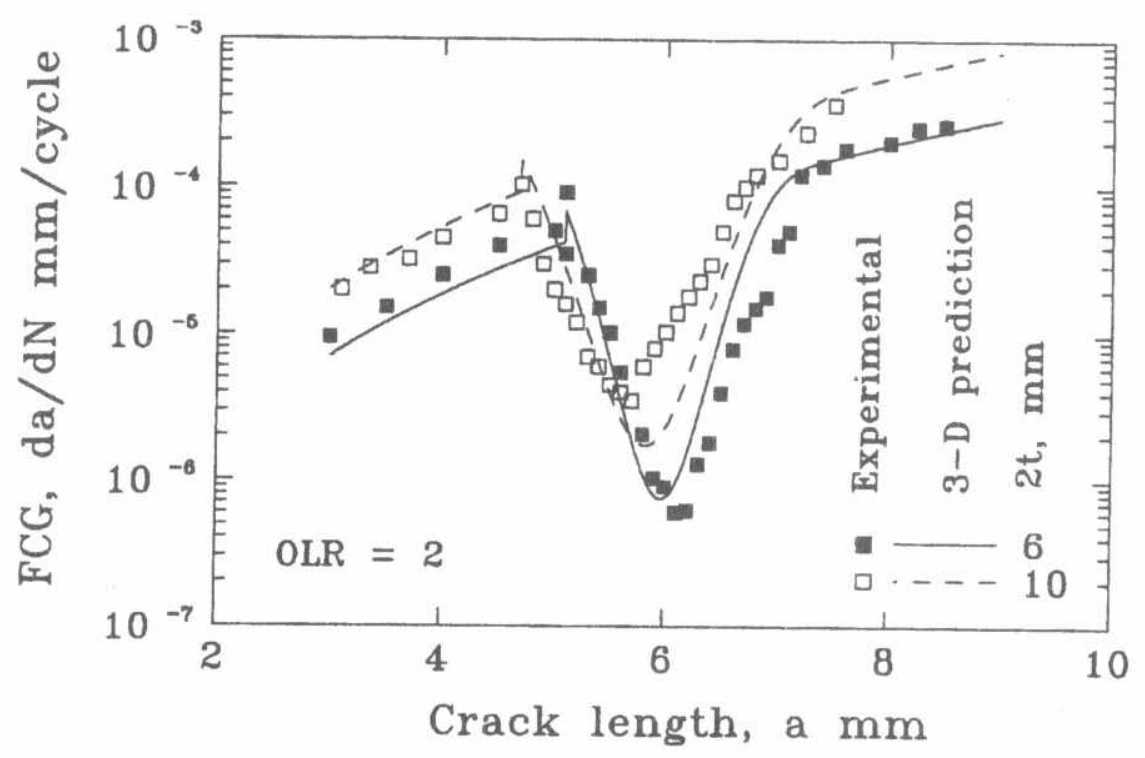

Fig.5 Comparison of experimental FCG data with the prediction from $3-D$ analysis for different specimen thicknesses

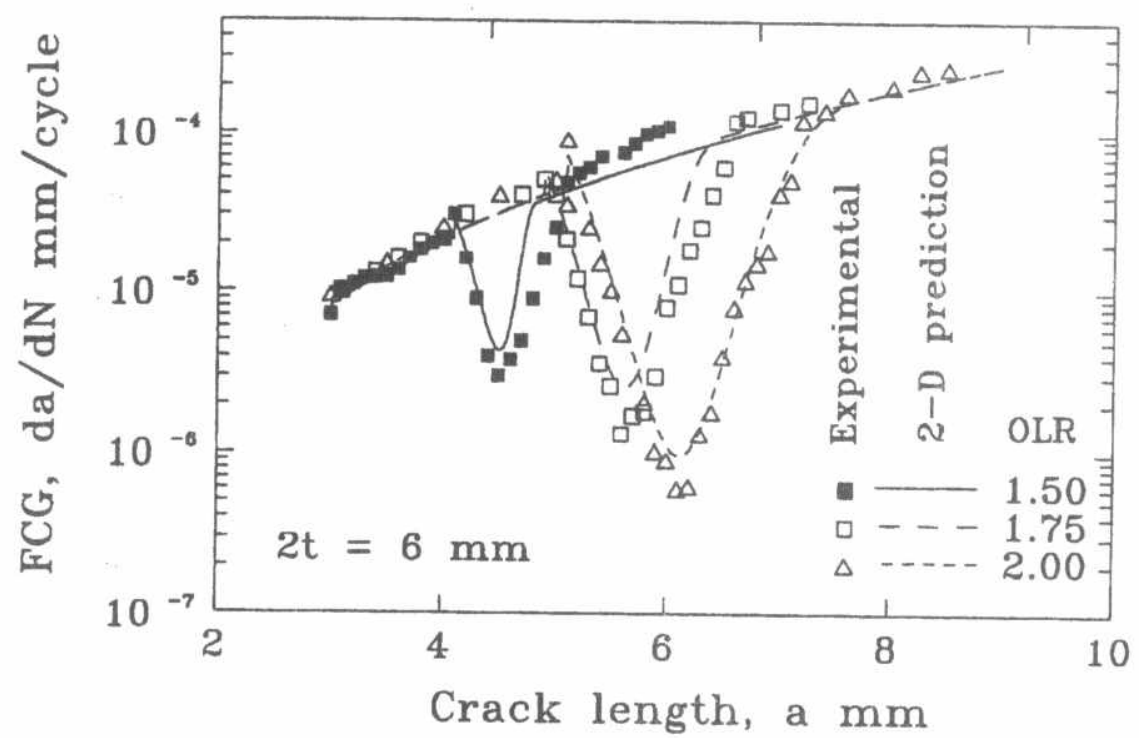

Fig. 6 Comparison of experimental FCG data with the prediction from $2-D$ analysis for different OLR. 